Racial stereotypes of Asian Americans and Pacific Islanders limit their access to leadership positions in higher education.

\title{
Asian American and Pacific Islander Faculty and the Bamboo Ceiling: Barriers to Leadership and Implications for Leadership Development
}

Fiona Lee

Diversity is an important priority for institutions of higher education (Shore, Chung-Herrera, Dean, Ehrhart, Jung, Randel, \& Singh, 2009). Racial and ethnic minorities are underrepresented among faculty ranks, and they also encounter negative biases in hiring (e.g., Tuitt, Sagaria, \& Turner, 2007), salary (Renzulli, Grant, \& Kathuria, 2006; Turner, González, \& Wood, 2008), and tenure (e.g., Harris, 2007; Williams \& Williams, 2006) decisions. There is a general assumption that Asian Pacific Islander Americans (APIAs), commonly seen as "model minorities," may not be subject to such biases. This perception is partly due to the fact that approximately $52.3 \%$ of APIAs have attained a bachelor's degree or higher, while the same statistic is $35 \%$ for other racial minority groups such as Black and Latinx populations (U.S. Census Bureau, 2016). Compared to Black and Latinx working adults, there is a higher proportion of APIAs in high-status, high-paying careers such as medical scientists, computer engineers, and post-secondary educators (U.S. Census Bureau, 2016).

However, despite their apparent educational, economic, and professional success, APIAs remain underrepresented in positions of leadership. This phenomenon, known as the "bamboo ceiling," has been observed in multiple domains (Hyun, 2005). For example, within Fortune 500 companies, fewer than $2 \%$ of executives are APIAs, less than Whites, Blacks, and Latinx (Eagly \& Chin, 2010; Le, 2012). In the Silicon Valley, APIAs represent the largest proportion of employees (exceeding even Whites), but White employees are 154\% more likely to be executives compared to APIAs (Gee, Peck, \& Wong, 2015). In law, 11\% of associates, but only 3\% of law-firm partners, are APIA (National Association for Law Placement, 2016).

This is the author manuscript accepted for publication and has undergone full peer review but has not been through the copyediting, typesetting, pagination and proofreading process, which may lead to differences between this version and the Version of Record. Please cite this article as doi: 10.1002/he.20326.

This article is protected by copyright. All rights reserved. 


\section{Reasons Underlying the Bamboo Ceiling}

A few studies have explored whether the bamboo ceiling exists within higher education. For example, Lee (2002) utilized multiple regression techniques to analyze data from a nationally representative survey and found no evidence that APIA faculty were paid less than their White counterparts (Lee, 2002). Although evidence indicated that activities associated with higher salaries for White faculty (e.g., being an associate professor) did not have the same beneficial effects on salary for APIA faculty, activities associated with higher salaries for APIA faculty (e.g., service) did not have the same beneficial effects for White faculty.

A different picture emerges when exploring faculty outcomes that are associated with power and status. Yan and Museus (2013) also used multiple regression analysis techniques to analyze nationally representative survey data examining differences in promotion to tenure between faculty of different racial groups. The results showed that faculty of color had a lower probability of being tenured than White faculty, but the disadvantage was most pronounced for APIA faculty. Similar observations have been evident when examining faculty in leadership positions. Although APIAs hold $7 \%$ of full-time tenure track faculty positions, more than any other racial minority group, APIAs constitute only $3 \%$ of deans, $2 \%$ of chief academic officers, and $1.5 \%$ of college presidents (Davis \& Huang, 2013). Overall, it appears that, while APIA faculty do not face a salary disadvantage, the bamboo ceiling is evident in higher education.

Several reasons have been proposed to explain the bamboo ceiling. Some researchers have suggested that, despite being well-represented among professorial ranks, APIAs hold tenure positions for shorter duration, on average, than their White counterparts. In other words, there may be a pipeline issue and APIAs may not be "senior enough" or "accomplished enough" to qualify for leadership positions (Yamagata-Noji, 2005). Others have conjectured that the bamboo ceiling can be attributed to Confucian and collectivist values endorsed by many Asian cultures, values that encourage "blending in" and eschew "standing out" (Akutagawa, 2013; Hyun, 2005; Zane, Sue, Hu, \& Kwon, 1991). As such, APIAs may not value leadership positions in more individualistic dominant cultures such as the U.S. where leaders are expected to differentiate themselves from the group. Still others have suggested that, compared to other minority groups, APIAs are more likely to be immigrants and thus 
less familiar with U.S. cultural norms. This may undermine APIAs' ability to achieve positions of leadership in U.S. institutions.

The bamboo ceiling may also be a result of racial stereotypes of APIAs as technically competent but unsociable. For example, APIAs are commonly described with adjectives such as hardworking, disciplined, and intelligent; but also with adjectives such as cold, shy, uptight, reserved, and lacking in charisma (Berdahl \& Min, 2012; Cheng, Lee, \& Benet-Martinez, 2006; Osajima, 2005; Wong, Lai, Nagasawa, \& Lin, 1998). These stereotypes of APIAs as high in technical competence and low in sociability contribute to perceptions of APIAs as "nerds" (Kibria, 2003), or people who are fit for technical jobs in technology or engineering, but unfit for jobs that require social skills such as public relations or retail (Lai \& Barbcock, 2013; Leong, 2014; Sy, Shore, Strauss, Shore, Tram, Whiteley, \& Ikeda-Muromachi, 2010).

Stereotypes of APIAs as unsocial undermine perceptions of APIAs as effective leaders (Sy, Tram, \& Leong, 2017; Woo, 2000). When asked to list characteristics of a good leader, the most commonly listed items are social skills such as communication, charisma, and team building (Madlock, 2003). Yet, these are precisely the areas in which Asians are believed to be deficient because of racial stereotypes. According to role congruity theory, when expectations associated with the leadership role conflict with group-based stereotypes associated with APIAs, APIAs are less likely chosen as leaders (Eagly \& Karau, 2002; Heilman, 2001).

Stereotypes of APIAs as technically competent can also undermine APIAs' ability to ascend to leadership positions. According to system justification theory, racial minorities are underrepresented in leadership positions because people are motivated to maintain the current hierarchy where leadership positions are predominantly assumed by members of the majority group (Jost, Pelham, Sheldon, \& Sullivan, 2003). The relatively "positive" stereotype of APIAs as technically competent makes APIAs appear especially threatening to the current hierarchy (Berdahl \& Min, 2012; Maddux, Galinsky, Cuddy, \& Polifroni, 2008). In addition, this positive stereotype creates the impression that APIAs are less oppressed than other marginalized groups, strengthening the motivation to preserve the existing hierarchy (Kay, Czaplinski, \& Jost, 2009). 


\section{Testing Explanations of the Bamboo Ceiling}

The explanations that have been offered to explain the bamboo ceiling are largely speculative, and it is still unknown why it exists and how it can be attenuated. In this chapter, we address this gap by exploring the bamboo ceiling within higher education. First, we use a large dataset of faculty in U.S. colleges and universities to examine the role of seniority, performance, value of service, and foreignness in accounting for the bamboo ceiling. Second, we conducted an experiment to examine the causal effect of APIA stereotypes on the bamboo ceiling.

\section{Study 1: Survey of U.S. Faculty Members}

We used logistic regression techniques to analyze the 2010 data from the Higher Education Research Initiative (HERI) Faculty Survey, which is a national survey of faculty from public and private 2- and 4-year U.S. colleges and universities. These data included 35,029 faculty members, and 52.8\% were male, $46.9 \%$ were female, and the remainder did not identify either gender option. In addition, 59.7\% were 54 years-old or younger $(59.7 \%)$. With regard to race, $89.5 \%$ self-identified as White, followed by APIA (5\%), Black (2.8\%), and Latinx (2.7\%). Leadership was measured by whether respondents served as Department Chair, Dean, Provost, Vice President, or President during their academic career $(0=$ No, $1=$ Yes $)$.

Does the Bamboo Ceiling Exist? We first examined whether APIA faculty were less likely than faculty of other races to serve in leadership positions. A binary logistic regression was used to examine the relationship between faculty race and leadership. The model was statistically significant $\left(\chi^{2}(3)=93.72, p<.001\right)$. Race, with APIA faculty as the reference category, was significantly and negatively related to holding a leadership position. Compared to APIA faculty, White (odds ratio=1.74, $B=0.58, p<.001$ ), Black (odds ratio=1.71, $B=0.53, p<.001$ ), and Latinx (odds ratio=1.51, $B=0.41, p<.001)$ faculty were all more likely to hold leadership positions.

How Can We Explain the Bamboo Ceiling? Next, we examined the extent to which previously offered explanations for the bamboo ceiling account for it. To examine whether APIAs were underrepresented in leadership because they were not "senior enough," we explored interactions between race and seniority (race $\mathrm{x}$ academic rank, race $\mathrm{x}$ tenure status). Neither interaction effect was 
significant (odds ratio $=0.84, B=-.17, p=.081$ and odds ratio $=0.74, B=-.30, p=.119$ respectively). That is, the salience of the bamboo ceiling (or lower likelihood of APIAs to attain leadership position) was the same at different levels of rank and tenure status.

To examine whether APIAs were underrepresented in leadership because they were not "accomplished enough," we examined the interaction between race and professional accomplishment (self-reported number of publications). The interaction effect was also not significant (odds ratio $=0.95, B=-.05, p=.364)$. In short, the size of the bamboo ceiling was the same regardless of faculty accomplishment.

To examine whether APIAs were underrepresented in leadership because they were unfamiliar with U.S. culture, we examined two interactions: (1) race x U.S. citizenship status, and (2) race $\mathrm{x}$ English as a native language. We reasoned that non-U.S. citizens and non-native English speakers are more likely to have lived outside of the U.S. and thus are less familiar with U.S. culture. Neither interaction was significant (odds ratio $=0.74, B=-.30, p=.111$ and odds ratio=1.30, $B=.26, p$ $=.130$ respectively). Lastly, we examined the interaction between race $\mathrm{x}$ perceived value of service (measured by the survey item "Personally, how important to you is service?"). Again, the interaction was not significant, (odds ratio $=0.93, B=-.07, p=.438$ ).

We further examined the effect of these explanatory variables together with two nested binary logistic regression models. The first model included all the explanatory variables, and was statistically significant $\left(\chi^{2}(8)=2250.36, p<.001\right)$. Faculty who were tenured, higher ranked, native-English speakers, more motivated to serve, and published less were more likely to be leaders. When faculty race (with APIAs as the reference category) was added in the second model, the model remained significant, $\chi^{2}(11)=2269.85, p<.001$, and it significantly improved model fit $\left(\chi^{2}(3)=19.48 p<.001\right)$. In short, after controlling for the explanatory variables, APIA faculty were still less likely to be leaders that White, Latinx, and Black faculty.

\section{Study 2: Experiment of APIA Stereotypes and Leadership}

Next, we used an experimental paradigm to examine how stereotypes of APIAs affected their leadership in higher education. We recruited 178 working adults $(58.4 \%$ female; average age $=36.27$; 
75.3\% White, 10.7\% APIA, 10.7\% Black, 4.5\% Latinx, 1.7\%) from Amazon's Mechanical Turk. Participants filled out an online survey where they were told to evaluate a faculty member as a potential candidate for a leadership position as president of a university. We experimentally manipulated the race of the faculty, such that they either had a prototypically APIA name (Hanyu Lee) or a prototypically White name (Jaime Peterson). We also manipulated the faculty's skills by giving participants a job performance report. These included 5 skills related to technical competence (e.g., "publishing research papers") and 5 skills related to sociability (e.g., "being an excellent team member"). The candidates either had skills that were consistent (high ratings on technical competence and low ratings on social skills) or inconsistent (high ratings on social skills and low ratings on technical competence) with APIA stereotypes.

Next, participants rated whether the faculty (1) would do a "good job" as president, and (2) "should be hired" as the president. Control variables included participants' ratings of whether the faculty members were "qualified" for the position of president, and participants' endorsement of APIA stereotypes as measured by the Scale of Anti-Asian American Stereotypes (SAAAS; Lin, Kwan, Cheung, \& Fiske, 2005).

Stereotype-Consistent APIAs vs. Whites with Identical Skills. We first compared perceived leadership effectiveness between stereotype-consistent APIAs (e.g., candidate named "Hanyu Lee") and Whites (e.g., candidate named "Jaime Peterson") with identical skills (i.e., both candidates had high technical competence/low sociability). We conducted analyses of covariance on perceived leadership effectiveness ("good job" and "should be hired") with the experimental condition as the independent variable. Perceived qualifications ("qualified"), participant race (APIA or not), SAAAS, and perceived gender of the faculty were included as covariates. A contrast showed that stereotype-consistent APIAs had lower ratings for "good job" $(F(2,169)=5.88, p=.003$; partial $\left.\eta^{2}=.06\right)$ and lower ratings for "should be hired" $\left(F(2,169)=7.23, p=.001\right.$; partial $\left.\eta^{2}=.08\right)$, compared to Whites with identical skills.

Stereotype-consistent vs. Stereotype-inconsistent APIAs. We conducted similar analyses with a contrast comparing perceived leadership effectiveness of stereotype-consistent APIAs (a candidate named "Hanyu Lee" with high technical competence/low sociability) and stereotype- 
inconsistent APIAs (a candidate named "Hanyu Lee" with low technical competence/high sociability). Stereotype-consistent APIAs had lower ratings for "good job" $(F(1,169)=11.72, p=$ 0.001 , partial $\eta 2=.065)$ and lower ratings for "should be hired" $(F(1,169)=14.18, p<0.001$, partial $\eta 2=.077)$ than stereotype-inconsistent APIAs. These findings suggest that racial stereotypes may underlie the bamboo ceiling.

\section{Recommendations for Leadership Development in Higher Education}

The present studies add to the small but growing body of literature on APIA faculty in higher education. It may not immediately be apparent that APIA faculty are disadvantaged. For example, APIA faculty salaries are comparable to those of White faculty (Lee, 2002). The representation of APIAs among faculty ranks are higher than the national population. Yet, when compared to other faculty with similar levels of preparation and productivity, APIA faculty are least likely to obtain tenure (Yan \& Museus, 2013) and report lowest levels of job satisfaction (Vargas, Ko, Robotham, \& Lee, 2018), compared to other groups.

The present chapter provides some evidence that APIA faculty are also least likely to serve in important leadership positions in higher education. Further, APIA faculty rising through the ranks, getting tenure, being more familiar with U.S. culture and norms, and valuing service do not equalize their odds of obtaining a leadership position with their Whites counterparts. To diminish this disparity, APIAs have to behave in stereotype-inconsistent manners. It may be the case that appearing sociable highlights APIAs' communication skills and charisma and, ironically, appearing less technically competent can reduce the extent to which APIAs are perceived as threatening. Thus, some advocacy groups advise APIAs to exaggerate their sociability and downplay their technical competence - essentially to act in ways that are inconsistent with the APIA stereotypes —in order to maximize their likelihood of advancing into leadership positions (Gee, Peck, \& Wong, 2015; Lai \& Babcock, 2013).

Whether such impression management strategies are actually effective in breaking down the bamboo ceiling outside of hypothetical, vignette-based experimental settings remains untested. Even if APIA faculty downplaying their technical competence may be helpful for achieving levels of executive leadership, such as a college presidency, this behavior could undermine other important 
career goals such as publishing, securing grants, or receiving tenure. Indeed, individual efforts to exaggerate some behaviors and deemphasize others may overcome one negative bias but do little to dismantle racial stereotypes. Rather, administrators in higher education can play a role in attenuating the harmful effects of these stereotypes. For example, institutional leaders can take the following steps to minimize the effect of racial stereotypes on APIA faculty members' access to leadership opportunities:

- Resist Impact of Stereotypes in Administrative Decision-Making. Administrators in higher education need to beware of their potential to marginalize and deny opportunities to APIAs based on stereotypes. Although APIAs may be well represented in higher education, there is unequivocal evidence that APIAs experience marginalization at various points in their career, such as when seeking tenure or leadership positions. Higher education administrators need to be especially aware of the effects of the bamboo ceiling during these critical stages of the pipeline.

- Use More Holistic Models of Leadership. Traditionally, leaders are expected to be highly individualistic — that is, independent, competitive, and agentic. This "Westernized" view of leadership often advantages individuals in the affluent White majority and makes it easy to overlook the leadership potential of individuals with different cultural orientations. This can be problematic. In large, complex organizations operating in fast-changing environments, effective leaders often have to be both individualistic and collectivistic (interdependent, cooperative, and communal), flexibly switching back and forth between different orientations depending on the demands of the situation. Administrators in higher education should make sure that they have more multifaceted models of effective leadership and provide more equitable hiring and promotional processes to ensure that leadership teams have persons with strengths in utilizing both individualistic and collectivist leadership styles.

- Provide Identity-Conscious Professional Development Opportunities. The present findings also underscore the importance of leadership development for APIA faculty. Executive leaders' mentoring and advocacy are imperative to the success of their mentees, but 
leaders in executive positions are predominantly White and much more likely to mentor individuals with similar social identities (Thomas, 2001). Given the dearth of APIAs in top leadership positions in higher education, APIA faculty may be less likely to receive mentoring around leadership. Thus, administrators should provide APIA faculty with mentoring and professional development opportunities (e.g., leadership training and coaching). When developing new mentoring relationships or professional development programs, executive leaders in higher education can also be more mindful of how APIA identity and other social identities (such as academic discipline, gender) shape leadership styles, and take this into account to engage the cultural strengths (e.g., collectivist orientations) of APIAs in the process.

\section{References}

Akutagawa, L. (2013). Breaking stereotypes: An Asian American's view of leadership development. Asian American Journal of Psychology, 4(4), 277-284.

American Council on Education (ACE). (2013). Raising voices, lifting leaders: Empowering APIA Pacific Islander American leadership in higher education. Retrieved from: https://bookstore.acenet.edu/products/raising-voices-lifting-leaders-empowering-APIApacific-islander-american-leadership-higher

Berdahl, J. L., \& Min, J. A. (2012). Prescriptive stereotypes and workplace consequences for East Asians in north America. Cultural Diversity \& Ethnic Minority Psychology, 18(2), 141-152.

Cheng, C., Lee, F., \& Benet-Martinez, V. (2006). Assimilation and Contrast Effects in Cultural Frame Switching (CFS): Bicultural Identity Integration (BII) and Valence of Cultural Cues. Journal of Cross Cultural Psychology, 37(6), 1-19

Davis, G. P., Huang, B. L., Lee, K., Yamagata-Noji, A., \& Suzuki, B. H. (2013). Raising Voices, Lifting Leaders: Empowering Asian Pacific Islander American leadership in Higher Education. American Council on Education.

Eagly, A. H., \& Carli, L. L. (2007). Women and the labyrinth of leadership. Harvard Business Review, 85(9), 62. 
Eagly, A. H., \& Chin, J. L. (2010). Diversity and leadership in a changing world. American Psychologist, 65(3), 216-224.

Eagly, A. H., \& Karau, S. J. (2002). Role congruity theory of prejudice toward female leaders. Psychological Review, 109, 573-598.

Gee, B., \& Peck, D. (2017). The illusion of Asian success: Scant progress for minorities in cracking the glass ceiling from 2007-2015. Retrieved from https://c.ymcdn.com/sites/www.ascendleadership.org/resource/resmgr/research/TheIllusionof AsianSuccess.pdf

Gee, B., Peck, D., \& Wong, J. (2015). Culture, caregiving, and health: Exploring the influence of culture on family caregiver experiences. Hidden in plain sight: Asian American leaders in Silicon Valley (Vol. 2014, pp. 1-8). New York: The Ascend Foundation.

Gee, G. C., Ro, A., Shariff-Marco, S., \& Chae, D. (2009). Racial discrimination and health among Asian Americans: Evidence, assessment, and directions for future research. Epidemiologic Reviews, 31(3), 130-51.

Harris, T.M. (2007). Black feminist thought and cultural contracts: Understanding the intersection and negotiation of racial, gendered, and professional identities in the academy. In K. G. Hendrix (Ed.), Neither White Nor Male: Female Faculty of Color; New Directions for Teaching and Learning (Vol. 110, pp. 55-64). San Francisco, CA: Jossey-Bass.

Heilman, M. E. (2001). Description and prescription: How gender stereo- types prevent women's ascent up the organizational ladder. Journal of Social Issues, 57(4), 657-674.

Higher Education Research Initiative (HERI). (1989-2016). HERI faculty survey. Retrieved from: http:/heri.ucla.edu/heri-faculty-survey/

Hyun, J. (2005). Breaking the Bamboo Ceiling: Career Strategies for Asians. Harper Collins.

Jost, J.T., Pelham, B.W., Sheldon, O., \& Sullivan, B.N. (2003). Social inequality and the reduction of ideological dissonance on behalf of the system: Evidence of enhanced system justification among the disadvantaged. European Journal of Social Psychology, 33, 13-36. 
Kawahara, D. M., Pal, M. S., \& Chin, J. L. (2013). The leadership experiences of Asian Americans. Asian American Journal of Psychology, 4(4), 240-248.

Kay, A.C., Czáplinski, S., \& Jost, J.T. (2009). Left-right ideological differences in system justification following exposure to complementary versus noncomplementary stereotype exemplars. European Journal of Social Psychology, 39, 290-298.

Kibria, N. (2003). Becoming Asian American: Second-generation Chinese and Korean American identities. Maryland: John Hopkins University Press.

Kim, A., \& Yeh, C. J. (2002). Stereotypes of Asian American Students.Eric Digest, 172(1), 1-4.

Lai, L., \& Babcock, L. C. (2013). Asian Americans and workplace discrimination: The interplay between sex of evaluators and the perception of social skills. Journal of Organizational Behavior, 34(3), 310-326.

Le, C. N. (2012, May 6). 14 important statistics about Asian Americans. Retrieved from www.Asiannation.org/14-statistics.shtml

Lee, S. (2002). Do AAPI faculty face a glass ceiling in higher education? American Educational Research Journal, 39(3), 695724.

Leong, F. T. L. (2014). Career development and vocational behavior of racial and ethnic minorities. New York, NY: Psychology Press.

Lin, M. H., Kwan, V.S.Y., Cheung, A., \& Fiske, S. T. (2005). Stereotype Content Model explains prejudice for an envied outgroup: Scale of anti-Asian American stereotypes. Personality \& Social Psychology Bulletin, 31(1), 34-47.

Louie, K. B. (2000). Asian American women and social advocacy. In J. L. Chin (Ed.), Relationships among Asian American women (pp. 13-23). Washington, DC: American Psychological Association.

Maddux, W. W., Galinsky, A. D., Cuddy, A. J. C., \& Polifroni, M. (2008). When being a model minority is good . . . and bad: Realistic threat explains negativity toward Asian Americans. Personality \& Social Psychology Bulletin, 34(1), 74-89. 
Madlock, P. E. (2008). The link between leadership style, communicator competence, and employee satisfaction. Journal of Business Communication, 45(1), 61-78.

Museus, S. D., \& Kiang, P. N. (2009). Deconstructing the model minority myth and how it contributes to the invisible minority reality in higher education research. New Directions for Institutional Research, 2009(142), 5-15.

National Association for Law Placement (NALP). (2015). Women, Black/African-American associates lose ground at major U.S. law firms. Retrieved from: https://www.nalp.org/lawfirmdiversity_nov2015.

Ng, J. C., Lee, S. S., \& Pak, Y. K. (2007). Contesting the model minority and perpetual foreigner stereotypes: A critical review of literature on Asian Americans in education. Review of Research in Education, 31(1), 95-130.

Nye, J. L., \& Forsyth, D. R. (1991). The effects of prototype-based biases on leadership appraisals A test of leadership categorization theory. Small Group Research, 22(3), 360-379.

Osajima, K. (2005). Asian Americans as the model minority: An analysis of the popular press images in the 1960s and 1980s. In K. A. Ono (Ed.), A companion to Asian American Studies (pp. 215-225). Malden, MA: Blackwell Publishing.

Renzulli, L.A., Grant, L. \& Kathuria, S. (2006). Race, gender, and the wage gap: Comparing faculty salaries in Predominantly White and Historically Black Colleges and Universities. Gender \& Society, 20(4), 491-510.

Renzulli, L.A., Grant, L. and Kathuria, S. (2006), "Race, gender, and the wage gap: Comparing faculty salaries in predominantly White and historically Black colleges and universities". Gender and Society, Vol. 20 pp. 491-510.

Ruttimann, J. (2009). Breaking through the "bamboo ceiling" for Asian American scientists. Retrieved from https://www.sciencemag.org/features/2009/05/breaking-through-bambooceiling-asian-american-scientists. 
Shore, L. M., Chung-Herrera, B. G., Dean, M. A., Ehrhart, K. H., Jung, D. I., Randel, A. E., \& Singh, G. (2009). Diversity in organizations: Where are we now and where are we going? Human Resource Management Review, 19(2), 117-133.

Shek, Y. L. (2006). Asian American masculinity: A review of the literature. Journal of Men's Studies, 14(3), 379-391.

Sue, D. W. (2005). Racism and the conspiracy of silence: Presidential address. Counseling Psychologist, 33(1), 100-114.

Swierczek, F. W. (1991). Leadership and culture: Comparing Asian managers. Leadership \& Organization Development Journal, 12(7), 3-10.

Sy, T., Shore, L. M., Strauss, J., Shore, T. H., Tram, S., Whiteley, P., \& Ikeda-Muromachi, K. (2010). Leadership perceptions as a function of race-occupation fit: The case of Asian Americans. Journal of Applied Psychology, 95(5), 902-919.

Sy, T., Tram-Quon, S., \& Leung, A. (2017). Developing minority leaders: Key success factors of Asian Americans. Asian American Journal of Psychology, 8(2), 142-155.

Thomas, D. (2001). The truth about mentoring minorities: Race matters. Harvard Business Review, 79(4), 99-107.

Tran, A. G., \& Lee, R. M. (2014). You speak English well! Asian Americans' reactions to an exceptionalizing stereotype. Journal of Counseling Psychology, 61(3), 484-90.

Tuitt, F.A., Sagaria, M.A.D. and Turner, C.S.V. (2007). Signals and strategies in hiring faculty of color. In J.C. Smart (Ed.), Higher Education: Handbook of Theory and Research (pp. 497535). Netherlands: Springer.

Turner, C.S.V., González, J.C. and Wood, J.L. (2008). Faculty of color in academe: What 20 years of literature tells us. Journal of Diversity in Higher Education, 1(3), 139-168

U.S Census Bureau. (2016, April 21). Asian /Pacific American Heritage Month: May, 2016. Retrieved from: http://www.census.gov/newsroom/facts-for-features/2016/cb16-ff07.html. 
Vargas, E., Ko, A., Robotham, K., \& Lee, F. (2018). Counting heads vs. making heads count: The impact of authentic diversity on psychological outcomes for faculty of color. Equality, Diversity, and Inclusion: An International Journal, 37(8), 780-798.

Williams, B. N., \& Williams, S. M. (2006). Perceptions of African American male junior faculty on promotion and tenure: Implications for community building and social capital. Teachers College Record, 108(2), 287-315.

Wong, P., Lai, C. F., Nagasawa, R., \& Lin, T. (1998). Asian Americans as a model minority: Selfperceptions and perceptions by other racial groups. Sociological perspectives, 41(1), 95-118.

Woo, D. (2000). Glass ceilings and Asian Americans: The new face of workplace barriers. California: Alta Mira Press.

Yamagata-Noji, A. (2005). Leadership development program in higher education: Asian Pacific American leaders in higher education — an oxymoron. Diversity in Higher Education, 5, 173206.

Yan, W., \& Museus, S. D. (2013). Asian American and Pacific Islander faculty and the glass ceiling in higher education. In S. D. Museus, R. T. Teranish, \& D. C. Maramba (Eds.), The misrepresented minority: New insights on Asian Americans and Pacific Islanders, and the implications for higher education (pp. 249-265). Sterling, VA: Stylus.

Zane, N. W., Sue, S., Hu, L. T., \& Kwon, J. H. (1991). Asian-American assertion: A social learning analysis of cultural differences. Journal of Counseling Psychology, 38(1), 63-70.

Zhou, M., \& Xiong, Y. S. (2005). The multifaceted American experiences of the children of Asian immigrants: Lessons for segmented assimilation. Ethnic and Racial Studies, 28(6), 11191152.

Fiona Lee is professor of psychology and associate dean of diversity, equity, inclusion, and professional development at the University of Michigan, Ann Arbor. 